\title{
Preliminary Study on Epidemic Prevention landscape Design of High-rise Residence Based on Healthy City
}

\author{
Guo Yunjia
}

School of architecture and art, Hebei College of architectural engineering, Qiaodong District, Zhangjiakou, Hebei,

China

382672351@qq.com

\begin{abstract}
SARS broke out all over the country in 2003. 321 cases of SARS occurred in Taoda Garden, a high-rise tower in Hong Kong. This incident caused the spread of infectious disease virus and the thinking of living space. In order to build a healthy city, this paper analyzes the advantages and disadvantages of high-rise residential buildings with high density, high plot ratio and less green space, and discusses how to build a dynamic, ecological, pleasant, organic and safe high-rise residential environment.
\end{abstract}

Keywords: Healthy City, high-rise residence, Landscape of epidemic prevention

\section{基于健康城市的高层住宅防疫景观设计初探}

\section{郭昀嘉}

河北建筑工程学院建筑与艺术学院, 桥东区, 张家口, 河北, 中国 382672351@qq.com

\section{摘要}

2003 年非典爆发在全国各地, 香港高层塔楼淘大花园非典病例高达 321 例, 该事件引起了传染性疾病 病毒的传播与居住空间的思考。以建设健康城市为目标，分析高密度、高容积率、绿地空间少的高层 住宅利弊，探讨如何建设具有活力、生态、宜人、有机、安全的高层住宅环境。

关键词：健康城市，高层住宅，防疫景观，初探

\section{1. 研究背景}

\section{1 健康城市理念}

在 1994 年 WHO (世界卫生组织) 正式对健康城市做 出解释, 即是一个不断开发、发展自然与社会环境, 并 不断扩展社会资源，在享受生命以及充分发挥潜能方面， 让人们能够互相支持的城市 ${ }^{[1]}$ 。“健康城市” 概念首次在 1984 年的 “2000 年健康多伦多会议” 提出, 旨在解决 城市健康以及相关问题 ${ }^{[2]}$ 。后来由 WHO 欧洲区实施” 健 康城市计划 “, 并作为一个全球性战略活动, 与 20 世 纪 90 年代初引入我国。“健康城市计划” 的实施重点在 于通过多部门协同合作, 从而加强以社区为基础的健康 促进活动, 从新的角度审视城市中出现的健康问题, 以 社区为媒介, 采取自下而上的策略来处理和解决公共卫 生问题 ${ }^{\left[{ }^{3}\right.}$ 。同时我国为响应 WHO 号召, 卫生部也开始在 部分城市建立健康城市试点, 正式启动健康城市项目。
在 2003 年 SARS（严重急性呼吸综合征）爆发下，我国 进入全面开展健康城市建设阶段, 对于预防和遏制疾病 的流行与发展产生了重要影响。

\section{2 人类公共安全健康问题}

一个国家以及地区人类健康状况体现在人类的死 亡水平、死亡原因构成以及变化趋势。随着自然环境变 化、社会经济发展以及医疗卫生事业进步，传染性疾病 和慢性非传染性疾病死亡构成比总体呈平稳上升趋势。 （如表 1、表 2) 
表 1 2010-2018 年我国传染性疾病死亡人数占总人 数 (单位\%)

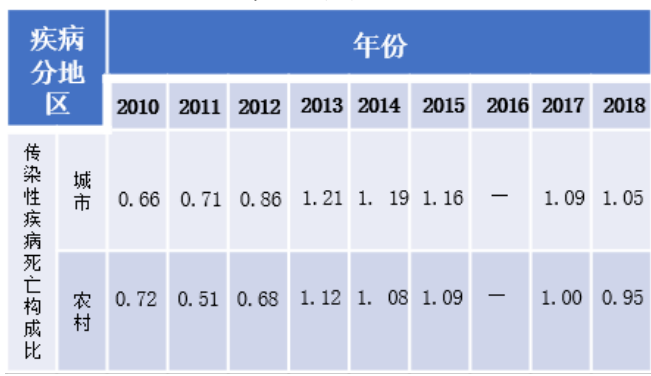

表 2 2010-2018 年我国慢性疾病死亡人数占总人数 (单位\%)

\begin{tabular}{|c|c|c|c|c|c|c|c|c|c|c|}
\hline \multirow{2}{*}{\multicolumn{2}{|c|}{$\begin{array}{c}\text { 僈珄病 } \\
\text { 死亡姁 } \\
\text { 成比 }\end{array}$}} & \multicolumn{9}{|c|}{ 年份 } \\
\hline & & \multirow{2}{*}{$\begin{array}{r}2010 \\
20.88\end{array}$} & \multirow{2}{*}{$\begin{array}{r}2011 \\
21.30\end{array}$} & \multirow{2}{*}{$\begin{array}{l}2012 \\
21.45\end{array}$} & \multirow{2}{*}{\begin{tabular}{|l|}
2013 \\
21.60 \\
\end{tabular}} & \multirow{2}{*}{$\begin{array}{l}2014 \\
22.10\end{array}$} & \multirow{2}{*}{$\begin{array}{l}2015 \\
21.98\end{array}$} & \multirow{2}{*}{\begin{tabular}{c|}
2016 \\
22.58
\end{tabular}} & \multirow{2}{*}{\begin{tabular}{|l|}
2017 \\
23.00 \\
\end{tabular}} & \multirow{2}{*}{\begin{tabular}{|l|}
2018 \\
23.2
\end{tabular}} \\
\hline & 城市 & & & & & & & & & \\
\hline & 农村 & 17.86 & 19.37 & 18.11 & 21. 90 & 21.68 & 21.84 & = 22.24 & 22. 73 & 23. \\
\hline \multirow{2}{*}{$\begin{array}{c}\text { 脑血管病 } \\
\text { 死亡构成 } \\
\text { 比 }\end{array}$} & 城市 & 20.23 & 20.22 & 19.61 & 20.27 & 20.41 & 20.63 & 20.58 & 20.56 & 20. \\
\hline & 农村 & 23. 37 & 21. 72 & 20.61 & 22.92 & 22. 92 & 23. 17 & 23.26 & 23. 18 & 23. \\
\hline \multirow{2}{*}{$\begin{array}{l}\text { 恶性肿 } \\
\text { 瘤死亡 } \\
\text { 构成比 }\end{array}$} & 城市 & 26.33 & 27.79 & 26.81 & 25.47 & 26. 17 & 26.44 & 26.06 & 26. 11 & 25. \\
\hline & 农村 & 23. 11 & 23. 62 & 22.96 & 22. 38 & 23. 02 & 23. 22 & 22.92 & 23.07 & 22. \\
\hline \multirow{2}{*}{$\begin{array}{l}\text { 呼吸系统 } \\
\text { 疾病死亡 } \\
\text { 构成比 }\end{array}$} & 城市 & 11.04 & 10. 56 & 12.32 & 12.37 & 12.03 & 11.80 & 11. 24 & 10.92 & 10. \\
\hline & 农村 & 14.15 & 13. 31 & 15.75 & 11.49 & 12.07 & 12.06 & 12.02 & 11. 57 & 11. \\
\hline \multirow{2}{*}{$\begin{array}{l}\text { 内分泌, } \\
\text { 营着和代 } \\
\text { 谢病病死 } \\
\text { 亡构成比 }\end{array}$} & 城市 & 2.93 & 3. 01 & 2. 82 & 2.76 & 2.86 & 3.10 & 3. 33 & 3. 33 & \\
\hline & 农村 & 1.66 & 1. 56 & 1.62 & 1. 79 & 1. 98 & 2. 15 & 2. 31 & 2. 40 & 2.4 \\
\hline \multirow{2}{*}{$\begin{array}{l}\text { 肌肉骨骼 } \\
\text { 和结缔组 } \\
\text { 织病死 } \\
\text { 亡构成比 }\end{array}$} & 城市 & 0.26 & 0.24 & 0.23 & 0.28 & 0.27 & 0.29 & 0.37 & 0.38 & 0.4 \\
\hline & 农村 & 0.14 & 0.21 & 0.21 & 0.24 & 0.25 & 0.23 & 0.25 & 0.26 & 0.2 \\
\hline \multirow{2}{*}{$\begin{array}{l}\text { 神经系统 } \\
\text { 病病亡比 } \\
\text { 枇 }\end{array}$} & 城市 & 0.94 & 1. 23 & 1. 12 & 1. 11 & 1. 12 & 1. 11 & 1. 22 & 1.27 & 1.3 \\
\hline & 农村 & 0.62 & 0.76 & 0.95 & 1.04 & 1.00 & 0.98 & 1. 11 & 1. 12 & 1.2 \\
\hline
\end{tabular}

传染性疾病最早出现在一万年以前的狩猎采集经 济时代, 人类以小型部落聚集、生活, 在某种意义上降 低了传染病风险, 因为传染性疾病传播的前提是人口密 度高。而随着农业革命的到来, 由采集野生小麦转变为 有意识栽种, 后发展为半定居型的农耕生活方式, 自然 环境与人类生活方式发生巨大变化, 造成蚊虫繁殖、居 住环境不佳、人口密度相对稠密等多种不良影响, 最后 导致传播致病微生物变得容易。随着社会经济与现代医 学的共同进步, 传染性疾病退出疾病主流, 直至 20 世 纪末新发传染病的诞生。2003 年 WHO (世界卫生组织) 曾对新发传染病做出说明, 是一种由新型病原微生物所 引起的传染性疾病。近年来, COVID-19 (新型冠状病毒 肺炎)、SARS (严重急性呼吸综合征)、甲型 H1N1 流感 等多种新发传染病正在威胁全球公共卫生健康。(表 3)
表 3 COVID-19 (新型冠状病毒肺炎) 疫情全球数据

\begin{tabular}{|c|c|c|c|c|c|}
\hline \multirow{2}{*}{\multicolumn{2}{|c|}{$\begin{array}{c}\text { 新冠肺炎疫情 } \\
\text { 数据 }\end{array}$}} & \multicolumn{4}{|c|}{ 年份 } \\
\hline & & \multirow{2}{*}{$\begin{array}{l}\text { 累计确 } \\
\text { 诊 } \\
82954\end{array}$} & \multirow{2}{*}{$\begin{array}{l}\text { 累计治 } \\
\text { 會 } \\
78238\end{array}$} & \multirow{2}{*}{ 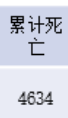 } & \multirow{2}{*}{$\begin{array}{c}\text { 新增 } \\
-\end{array}$} \\
\hline $\begin{array}{c}\text { 截止2020年5月 } \\
\text { 17日24点 }\end{array}$ & 中国 & & & & \\
\hline \multirow{10}{*}{$\begin{array}{l}\text { 截止2020年5 } \\
\text { 月18日18点 }\end{array}$} & 美国 & 1486375 & - & 89549 & 29534 \\
\hline & 俄罗斯 & 281752 & - & 2631 & - \\
\hline & 西班牙 & 276505 & - & 27650 & - \\
\hline & 英国 & 243695 & - & 34636 & 3530 \\
\hline & 巴西 & 241080 & - & 16118 & 7938 \\
\hline & 意大利 & 225435 & - & 31908 & 675 \\
\hline & 德国 & 174355 & - & 7914 & - \\
\hline & 土耳其 & 149435 & - & 4140 & 1368 \\
\hline & 法国 & 142411 & - & 28108 & 120 \\
\hline & 全球总数据 & 4698514 & 283217 & 314225 & - \\
\hline
\end{tabular}

国务院于 2017 年 1 月 22 日发布了《中国防治慢性 病中长期规划 (2017-2025 年)》, 主要目的是加强慢性 病防治工作、降低疾病负担、提高居民健康期望寿命, 努力全方位、全周期保障人民健康。根据国家统计局 2018 年居民主要疾病死因构成统计数据, 我国城市、农 村居民慢性疾病死亡人数占总死亡人数比例分别高达 $85.75 \% 、 84.81 \%$, 高血压、高血脂以及糖尿病等慢性病 已成为我国公民健康最大的威胁。

\section{2. 高层住宅建筑缺陷分析}

\section{1 城市住宅主要供给模式}

政府应对 COVID-19 (新型冠状病毒肺炎) 启动国务 院联防联控机制。各地区多部门协同合作，为进一步加 强疫情防控, 提出小区实施封闭式管理, 力求控制住疫 情蔓延, 住宅成为防控疫情的关键点 ${ }^{[4]}$ 。

随着社会经济的快速发展, 人口大量涌入城市, 导 致中国住宅势不可挡的开发浪潮, 由于住宅用地受限, 住宅建设大多转向高密度、高容积率、绿地空间少的高 层住宅。高层住宅依赖单一封闭的垂直交通方式、共享 的密闭通风井、高落差污水系统, 从而变成疫情非常容 易扩散的空间 ${ }^{[5]}$ 。

\section{2 高层住宅建筑通风缺陷}

通风。大部分高层住宅区别于传统南北通透的建筑, 相对地住宅内空气也就无法自然流通, 空气浊度升高, 造成传染性疾病病毒传播的潜在危害性。为控制 SARS 交 叉感染, 2003 年 4 月 30 日建设部办公厅、卫生部办公 厅印发了《关于做好建筑空调通风系统预防非典型肺炎 工作的紧急通知》。德国、日本等多国专家研究发现, 通 风可以有效降低病毒浓度。包括此次新冠肺炎疫情中, 
也出现住宅楼的跨层传播。

\section{3 高层住宅建筑排污缺陷}

排污。大批高层与多层住宅建筑大多采用由上至下 设置直立式污水管道, 以横向管道连接各楼层, 从而收 集、排放居民的生活污水。地漏的设置在某种角度帮助 了我们的生活, 但也带来排水不畅、下层管道堵塞、上 层污水倒流等不良现象, 也存在疾病传播的隐患。

\section{3 设计策略}

\section{1 地形设计}

a. 分隔空间。利用平坦、起伏平缓与陡峭、崎岖等 地形相互交叉应用于住宅户外空间, 如聚会等大型娱乐 活动, 又或者为青少年打造兴奋、恣意地场所, 塑造多 重空间感受, 满足住宅区内不同年龄、文化水平、兴趣 爱好的住户。b. 控制视线。采用坡度与地形轮廓线变化, 打造住宅区景观韵律与住宅景观层次。设置住户与同一 景观构筑物的不同的高度与距离关系, 在实与虚之中产 生不同的感受。c. 改善小气候。由于太阳照射角度的不 同，不同季节的日照、阴影方向也有很大差异。同一天 不同时间段在建筑体上日照所产生的阴影方向、范围也 不尽相同。应用至小区内的景观设计中，应考虑季节因 素, 合理有效地利用日照, 划定各空间内的功能属性以 及考虑使用者需求, 满足空间内时节活动特征。如冬季 休闲空间应使用朝南的坡向，确保充足阳光照射。

\section{2 植物设计（防疫植物、康复植物、色彩)}

在《风景园林设计要素》中, 将植物作用分为四类, 分别是功能、建造、观赏、美学。通过植物构成空间、 形成障景、控制私密性等; 不同植物的大小、外形、色 彩、类型、质地也带来不同的观赏特性 (表 4); 植物的 美学功能也具有完善、统一、强调、识别、软化、框景, 从美学的角度看, 运用植物将建筑与其周围环境相连结 在一起, 统一和协调环境中其他不和谐因素, 突出住宅 区景观中的节点与分区, 削弱构筑物粗糙、呆板的外观, 以及限制视线。
表 4 观赏性植物季节、色系划分

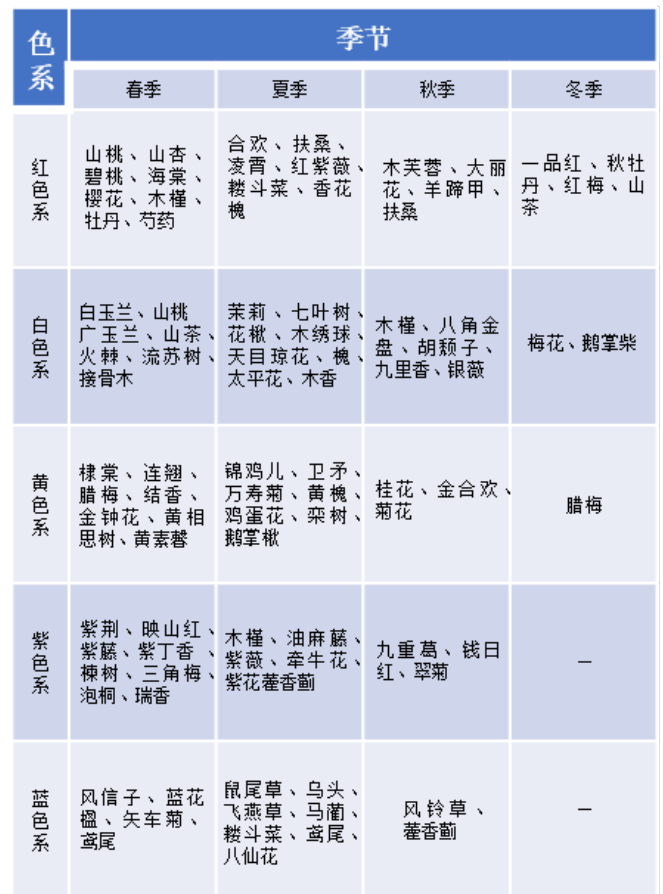

\section{3 建筑物改造}

为应对高层住宅建筑内缺陷, 从以下方面进行改造。 首先恢复与提高建筑物自然通风性能, 最大程度地利用 自然通风。其次在 “风匣效应” 的影响下，建筑内的通 风井成为了厨房、卫生间污气串流的地方, 应采取相应 技术手段，提高建筑体内的通风与排放污气的能力。同 时清洁、消毒高层住宅建筑内地通风井, 降低病毒从通 风井扩散地风险。

\section{4 铺装设计}

结合住宅区内建筑特点、风格，在色彩、质感、尺 度选择、铺装形式等方面, 配合住宅区景观的设计风格, 保持住宅区内所有要素风格的统一。首先划分住宅区内 道路等级, 分为 3 级, I 级为连接各住宅组团的、公共 建筑与主景观的行车道; II 级为各住宅组团内, 与建筑 体、景观的中型道路; III级为景观之间衔接的步行道、 小径等。根据空间场所属性，搭配以符合使用者特性的 图案、颜色加以铺装, 同时考虑材料的抗菌性、耐磨性, 应对疾病病毒的传播。如儿童活动空间应采用鉦丽的颜 色、图案加以搭配。同时考虑儿童活泼好动的特性, 混 合使用如沥青、水泥方砖等硬质材料以及橡胶垫、草坪 等软质材料。

硬质铺装。a. 整体铺地。采用沥青整体铺地, 该材 料造价低且耐受性强、平整度高, 常常用在人流量、车 流量密集的住区主干道。但由于减震效果差、外观呆板 不适用于住宅区活动场所。 b. 快料铺地。用花岗石、青 
石板、混凝土板铺地应用于住宅区活动场所, 造型优美。 应对天气变化, 将材料表面打磨成凹凸不平, 降低住宅 区内老人、儿童滑倒、摔伤的危险性。经实验证明, 花 岗岩的抗细菌再生能力较好, 处于防控疾病的角度, 是 室外铺地较好的选择。c. 碎料铺地。采用石材、瓷砖的 边角料和我鸟卵石, 用于住宅区内的步道、小径等, 在节 约成本的同时达到美观、个性的目的。

软质铺装。即是用花卉、草地、灌木、乔木等植物 的地面铺装形态, 较于硬质铺装来说, 更加具有亲和力、 感染力。同时可塑性较强, 搭配周围植物, 使得该空间 变得更加生机勃勃。

\section{5 景观构筑物设计}

景观构筑物是住宅空间中的小型硬质景观, 提高造 景效果、优化住宅空间氛围。防疫景观构筑物主要设计 以下三个方面: a. 保健运动宣传型, 主要宣传与健康有 关的保健类运动, 丰富住户群体保健运动知识, 同时提 供保健、运动兴趣。b. 养生文化标志型, 宣扬我国传统 养生文化, 如道家天人合一、阴阳平衡思想以及中医养 生文化等。c. 实用康复型, 包括运动器械、室外座椅等, 是作为辅助住户健身活动的设施, 同时在设施材料上选 取抗菌性较好的, 避免交叉感染。

\section{6 水体设计}

水体可塑性强, 可以形成不同形态, 如平展如镜的 水池, 流动的叠、跌水和喷泉等。同时可以使空气凉爽、 降低噪音、灌溉土地。首先考虑安全性, 因儿童、孕妇、 老人等人群身体技能与平衡性处在较弱势, 水体景观设 计应考虑安全水深和防护措施, 如水体两侧设置护栏等, 以求减少溺水危险性。因大型水体景观施工造价较高, 且后期维护、管理以及使用都需要费用, 建议减少大型 水体以及水体数量, 且北方地区气候干旱多风, 考虑在 冬季水体景观关闭时, 是否会造成住户伤害的因素。

\section{项目基金}

本文为河北建筑工程学院硕士研究生创 新基金项目 XY202022《寒冷地区住宅建筑阴 影区冬季景观营造研究——石家庄市为例》 的阶段性成果之一。

\section{References}

[1] Regiona Office for Europe of World Health Organization. (1997)Twenty steps for developing a Healthy Cities project,3rd ed.In: Copenhagen.
[2] Leonard D. (2009) The healthy city: It's function and it's future. Health Promot Int,1(1):55-60.

[3] Ashton J, Grey P, Barnard K.(2006)Healthy cities: WHO's new public health initiative. Health Promot,1(3): 319-324.

[4] Wang Hh, Zhai Lj. (2003)"SARS" causes us to rethink the urban living environment. City, 6: 47-49.

[5] Yang Jy, Shi Bx, Shi Y, Li Yh. (2020) On the construction of multi-scale spatial epidemic prevention system in high-density cities. City planning, 3: 17-24. 